\title{
Does the Mutton Sheep Weather Index Insurance Promote the Mutton Sheep Industry? A Study based on the Endogenous Switching Regression Model
}

\author{
Yufei Gong, Yuanfeng Zhao* \\ College of Economics and Management, Inner Mongolia Agricultural University, Hohhot, \\ Inner Mongolia, China \\ *Corresponding Author.
}

\begin{abstract}
In 2018, as the first livestock weather index-based insurance product for grassland animal husbandry, the mutton sheep weather index insurance was officially listed as a subsidy agricultural insurance by the Government of the Inner Mongolia Autonomous Region, which was later in 2019 implemented throughout the Xilin Gol League of the autonomous region. Employing the endogenous switching regression model, this study investigates the factors influencing herdsmen's purchasing decisions, as well as the impact of mutton sheep weather index insurance on the mutton sheep industry scale, which are accomplished based on 308 survey data from herdsmen in the Xilin Gol League. The empirical results reveal that the age, age squared, pasture area and neighbors' purchasing intention constitute the significant influencing factors of the herdsmen's purchasing decisions, while the pasture area and net pastoral income affect the scale of mutton sheep farming prominently. Furthermore, according to the ATT results, the mutton sheep weather index insurance produces an insignificant impact on the sheep farming scale of herdsmen. The conclusions of this study suggest that the mutton sheep weather index insurance is not contrary to the cattle-increasing, sheep-reducing policy in the Inner Mongolia Autonomous Region, which also provide a solid theoretical basis for the promotion of the insurance throughout the autonomous region.
\end{abstract}

Keywords: Mutton sheep weather index insurance, herdsmen, mutton sheep industry, endogenous switching regression model, average treatment on the treated

\section{Introduction}

Agricultural index insurance, as a new type of agricultural insurance product, has been introduced following the single- and multi-coverage agricultural insurances [1]. In recent years, index insurance has gained widespread attention globally as an effective risk management instrument, which has shown remarkable effects in lowering uninsured systemic risks in the underdeveloped areas that lack commercial insurance products [2]. In simpler terms, index insurance is an insurance policy where the insurer settles a claim against the insured based on whether the actually observed index has reached the preset threshold. There are some principles that should be followed during the index selection. For instance, the index should be a random variable that is objective, observable, quantifiable and highly correlated with actual losses, i.e. some properties unaffected by human factors [3][4]. On the other hand, the threshold can be approximately regarded as a deductible in the conventional agricultural insurance [5]. That is, the insurer will not settle any claim against the insured if the measured index is lower than the threshold. However, once the measured index exceeds the threshold, the insurer needs to settle a claim against the insured according to the contract. As is well known, moral hazard and adverse selection have been recognized by both the academic and practical circles as the two foremost constraints on the development of conventional agricultural insurances. For conventional agricultural insurances, the final claim settlement is based on the post-disaster field loss assessments, which increase the regulatory and

ISSN: 0010-8189 
operating costs of insurance companies directly [6]. This is particularly the case in areas with sparse population densities. Regarding index insurances, they settle claims based on whether the actually observed index triggers the threshold, rather than on the loss assessment surveys. As a result, not only the moral hazard and adverse selection resulting from information asymmetry are weakened, but the need for a loss assessment survey is eliminated, thereby lowering the regulatory and operating costs directly for insurance companies.

In China, the agricultural index insurances have been introduced comparatively late than the foreign countries, which are developing rapidly, but are mostly weather index insurance products targeted to the planting industry, such as the rice and wheat weather index insurances[7]. In 2015, the weather index insurance for cattle and sheep in pastoral areas was officially put into trial operation in the Ulgai grassland, Xilin Gol League of the Inner Mongolia Autonomous Region, which marked a zero breakthrough in the livestock index insurance products in China. Subsequently, the aforementioned weather index insurance was officially listed as a premium subsidy project in 2018 by the Inner Mongolian government, and in 2019, implemented throughout the Xilin Gol League. Later, the weather index insurance for cattle and sheep in pastoral areas was officially renamed as the mutton sheep weather index insurance, and completed its transition from a commercial to a policy insurance.

To date, academic attention concerning index insurance has been focused on its qualitative aspects, such as the definition, the pros and cons analysis and the development course. In quantitative terms, only its demands and influencing factors have been analyzed in the literature. Despite unanimous recognition of index insurance as the future development direction of agricultural insurance, the impact of such insurances on the production behaviors of herdsmen (or peasants) in pilot areas have rarely been explored [8]. This is partially attributed to the small demand for index insurance, which restricts scholarly interest in researching its impact [9][10][11]. Another reason is the lack of sufficient field survey data from herdsmen (or peasants). The direct consequence of relevant research scarcity is the inability to evaluate corresponding policy effect in a reasonable and scientific way. In the meanwhile, whether a policy is effective or not, i.e. whether it has attained its preset goal, is the focus of most attention among all insurance parties, including the governments, insurers, and insured. Besides, evaluation of a policy not only allows the determination of its intrinsic value, but also enables comprehensive examination and analysis of various policy process stages, through which experiences and lessons can be summarized, thereby providing a reference for subsequent policy implementation.

Given implementation of the livestock index insurances in individual countries (e.g. Kenya and Mongolia) only, the efficacy evaluation of such agricultural insurances has rarely been accomplished abroad at present, which is even unexplored at home. Researching whether this type of weather index insurances affects the sheep breeding scale has strong policy implications. On the one hand, experts have discovered a seriously exceeding grazing capacity in most pastures around the world, whose direct consequences were the decline in productivity and the deterioration of grassland eco-environment [12]. On the other hand, many countries, including China, have enacted numerous laws and regulations for repairing damaged grassland ecosystems, such as the pasturing ban implemented in the Inner Mongolia Autonomous Region, which are supplemented by plenty of corresponding reward and subsidy measures. Assuming the implementation of sheep weather index insurance in pastoral areas indeed increases the sheep breeding scale, then the original intention of such agricultural insurance products is to raise the production costs of herdsmen caused by natural disasters, which is contrary to the reality as well as national policies. This provides a strong theoretical and practical basis for determining the necessity of widespread or adjusted promotion of such weather index insurances in the pastoral areas of the Inner Mongolia Autonomous Region and entire China.

Currently, discussion and research on the policy evaluation approaches under causal inference have been emerging in the academia. The problem is that during evaluation of a policy, the difference in a certain 
evaluation between treatment and control groups can hardly be attributed only to the impact of the policy. In experimental studies such as randomized trials, we easily get a "counterfactual situation" due to the random allocation of subjects into the treatment or control group, so that the aforementioned problem can be solved accordingly. Nevertheless, experimental research is inapplicable in the realm of policy evaluation, since the application of randomized research is hindered jointly by factors like high cost and individual intransigence. Numerous economic studies, including policy evaluation, are observational studies that come with confounding factors and selection bias. To explain or eliminate the biased estimates resulting from selection bias, differing assumptions are made in a variety of policy evaluation approaches.

In this study, the selection bias is explained using the endogenous switching regression model. That is, the observable and unobservable factors are regarded as the joint contributing factors to the selection. We deem whether the herdsmen purchase the sheep weather index insurance as a selection process. In consideration that herdsmen are a special kind of farmers, it is assumed that the herdsmen's purchasing intention for weather index insurance is linked directly to whether such insurance can increase the sheep breeding scale. In other words, the expected breeding scale of herdsmen will increase if they purchase the sheep weather index insurance, and vice versa. As mentioned above, due to the current low demand for index insurance, scholarly involvement in its efficacy research has been scarce as well. The endogenous switching regression model can, on the one hand, specifically examine the differences in sheep breeding scale between herdsmen in the treatment and control groups, which arise from the purchase of weather index insurance. On the other hand, the model enables analysis of factors influencing the purchasing behaviors of herdsmen for the sheep weather index insurance, which owes to the simultaneous regression of selection and outcome equations achieved by the full-information maximum likelihood (FIML) method. Thus, through application of the endogenous switching regression model, the influencing factors of herdsmen's insurance purchase can be identified, and the impact of purchasing mutton sheep weather index insurance on the sheep breeding scale can be analyzed.

\section{Data Sources and Statistical Description}

To fully comprehend the implementation status of mutton sheep weather index insurance in the Inner Mongolia Autonomous Region and to provide data support for solving scientific problems, our team conducted a half-month household survey in Xilin Gol League, Inner Mongolia Autonomous Region in August 2019. The survey was divided into two parts. Initially, our team selected 7 typical animal husbandry banners in Xilin Gol League as the survey locations, which were Xilinhot City, Xiwu Banner, Ulgai District, Dong Ujimqin Banner, Abaga Banner, Zhenglan Banner and Sonid Right Banner. At each survey location, our team members interviewed the relevant departments of banner-level governments and the heads of insurance companies, trying to obtain information about the problems encountered in the implementation of the insurance and the directions for future improvement from the insurer side. Afterwards, two sumus (townships) were selected randomly from each banner-level survey location, from each of which two gachas (villages) were further selected randomly to serve as the household survey sites. In the present survey, 328 questionnaires were collected in total, of which 308 were valid. Among the valid questionnaires, 174 were from the insured herder households and 134 were from the uninsured households.

Table 1 Variable definitions and descriptive statistics

\begin{tabular}{|c|c|c|c|}
\hline Variable & Mean & Standard deviation & Value assignment \\
\hline $\begin{array}{c}\text { Weather index } \\
\text { insurance }\end{array}$ & 0.56 & 0.50 & $1=$ Insured; $0=$ Uninsured \\
\hline $\begin{array}{c}\text { Mutton sheep } \\
\text { inventory }\end{array}$ & 430.87 & 335.14 & Stock quantity at the end of June \\
\hline
\end{tabular}

ISSN: 0010-8189 


\begin{tabular}{|c|c|c|c|}
\hline Age & 45.82 & 9.30 & Years \\
\hline Years of education & 7.91 & 2.96 & Years \\
\hline Years of grazing & 24.18 & 10.83 & Years \\
\hline $\begin{array}{l}\text { Household labor } \\
\text { force }\end{array}$ & 2.31 & 0.84 & Number of people \\
\hline $\begin{array}{l}\text { Experience as a } \\
\text { village cadre }\end{array}$ & 0.14 & 0.34 & $1=$ Yes $; 0=$ No \\
\hline $\begin{array}{c}\text { Distance from the } \\
\text { nearest township } \\
\text { government }\end{array}$ & 26.48 & 23.94 & $\mathrm{~km}$ \\
\hline Pasture area & 5429.47 & 6212.83 & $\begin{array}{l}\text { Owned + leased - rented pasture area } \\
\qquad(\mathrm{mu})\end{array}$ \\
\hline Net pastoral income & 19.47 & 17.40 & Income from livestock sale (yuan) \\
\hline Forage cost & 58262.60 & 49809.36 & yuan \\
\hline Shed area & 366.87 & 591.14 & $\mathrm{~m}^{2}$ \\
\hline Housing area & 159.54 & 107.25 & $\mathrm{~m}^{2}$ \\
\hline $\begin{array}{c}\text { Commercial life } \\
\text { insurance expenses }\end{array}$ & 2827.34 & 8666.71 & $\begin{array}{c}\text { Total commercial life insurance } \\
\text { expenses of family members (yuan) }\end{array}$ \\
\hline Grassland quality & 3.27 & 0.86 & $\begin{array}{l}1=\text { very poor; } 2=\text { poor; } 3=\text { fair; } 4= \\
\text { good; } 5=\text { very good }\end{array}$ \\
\hline $\begin{array}{l}\text { Grazing capacity } \\
\text { specification }\end{array}$ & 0.61 & 0.49 & $1=$ Clear; $0=$ Unclear \\
\hline $\begin{array}{c}\text { Neighbors' } \\
\text { purchasing } \\
\text { intention }\end{array}$ & 0.59 & 0.49 & $1=$ Purchased $; 0=$ Not purchased \\
\hline
\end{tabular}

Table 2 Average deviation statistics between the insured and uninsured households

\begin{tabular}{|c|c|c|c|}
\hline Variable & Insured household & Uninsured household & Average deviation \\
\hline Age & $45.82(0.62)$ & $45.83(0.93)$ & -0.01 \\
\hline Years of education & $8.20(0.20)$ & $7.53(0.28)$ & $0.67^{*}$ \\
\hline Years of grazing & $23.72(0.72)$ & $24.76(1.06)$ & -1.04 \\
\hline Household labor force & $2.30(0.56)$ & $2.33(0.82)$ & -0.03 \\
\hline $\begin{array}{c}\text { Experience as a village } \\
\text { cadre }\end{array}$ & $0.17(0.03)$ & $0.10(0.03)$ & 0.06 \\
\hline $\begin{array}{c}\text { Distance to the nearest } \\
\text { township government }\end{array}$ & $26.05(1.89)$ & $27.53(1.97)$ & -1.48 \\
\hline Pasture area & $4844.07(321.31)$ & $6397.35(701.61)$ & $-1553.29^{*}$ \\
\hline Net pastoral income & $207161.50(14129.61)$ & $185958.4(13155.44)$ & 21203.14 \\
\hline Forage cost & $59167.09(3548.38)$ & $57088.12(4631.64)$ & 2078.97 \\
\hline $\begin{array}{c}\text { Shed area } \\
\text { Housing area }\end{array}$ & $401.41(50.29)$ & $273.72(28.037)$ & $127.69^{*}$ \\
\hline $\begin{array}{c}\text { Commercial life } \\
\text { insurance expenses }\end{array}$ & $2684.97(536.69)$ & $2196.88(708.46)$ & 483 \\
\hline $\begin{array}{c}\text { Grassland quality } \\
\text { Grazing capacity } \\
\text { specification }\end{array}$ & $3.29(0.07)$ & $3.25(0.07)$ & 0.04 \\
\hline $\begin{array}{c}\text { Neighbors' purchasing } \\
\text { intention }\end{array}$ & $0.65(0.04)$ & $0.57(0.04)$ & 0.08 \\
\hline
\end{tabular}

ISSN: 0010-8189 


\begin{tabular}{|c|c|c|c|}
\hline $\begin{array}{c}\text { Mutton sheep } \\
\text { inventory }\end{array}$ & $437.56(24.98)$ & $422.19(29.66)$ & 15.37 \\
\hline
\end{tabular}

Note: The numbers in parentheses represent standard deviations; $* \mathrm{p}<0.1, * * \mathrm{p}<0.05, * * * \mathrm{p}<0.01$

From the above table, it is clear that the age difference between insured and uninsured households was insignificant. Most of the interviewed herders were around 45 years of age, and middle-aged and elderly people accounted for major proportions. The insured households exhibited significantly higher educational level than the uninsured households, indicating longer education received by them. Despite inter-group differences in the grazing years, number of family labors, experience as a village cadre and distance to the nearest township government, none of relevant average deviations passed the significance test. The average pasture area of the insured group was 4,844.07 mu, which was significantly smaller than the uninsured group's $6397.35 \mathrm{mu}$, suggesting that the uninsured herder households possessed more land resources than the insured households, showing statistical significance regarding the average deviation. In terms of net pastoral income and forage cost, no statistical significances were noted in average deviation, albeit higher values shown by the insured group than the uninsured. The average shed area occupied by the insured herder households $(401.41 \mathrm{~m} 2)$ was larger than the uninsured households (273.72 $\mathrm{m} 2$ ), revealing a significant average deviation. Moreover, the insured group exhibited higher housing area, commercial life insurance expenses, grassland quality and the awareness of grazing capacity regulations than the uninsured group, despite insignificant average deviations. The insured herder households had more neighbors who purchased the mutton sheep weather index insurance, presenting a significance average deviation. With regard to the mutton sheep inventory, insignificant average deviation was observed, although the insured herdsmen owned more sheep than the uninsured households.

\section{Model Description and Results Analysis}

Endogenous switching regression model is employed to investigate the factors influencing herdsmen's purchase of weather index insurance, as well as the impact of sheep weather index insurance on the sheep breeding scale in pastoral areas. The model comprises two stages, with the first stage involving the selection equation, and the second stage involving the outcome equations[13][14].

In the selection equation, whether a herdsman purchases the sheep weather index insurance is assumed to be a selection process. It is also assumed that all herdsmen are risk-neutral, whose production goal is always to expand the husbandry scale. Herdsmen's intention of purchasing the cattle-sheep weather index insurance is driven primarily by whether such purchase increases their expected livestock size. In other words, suppose the potential net increase in livestock brought by the purchase of weather index insurance is $\mathrm{D}_{\mathrm{N}}^{*}$, and the expected net increase in livestock without insurance purchase is $\mathrm{D}_{\mathrm{M}}^{*}$, the herdsmen will choose to purchase the sheep weather index insurance if $\mathrm{D}_{\mathrm{M}}^{*}-\mathrm{D}_{\mathrm{N}}^{*}=\mathrm{D}_{\mathrm{i}}^{*}>0$. However, $\mathrm{D}_{\mathrm{i}}^{*}$ is unobservable to researchers, meaning that the herdsmen determine whether the insurance purchase can increase their livestock size subjectively. Hence, the choice behavior of herdsmen is examined with the following latent variable model, which precisely constitutes the first stage in the endogenous switching regression model.

$$
D_{i}^{*}=Z_{i} \beta+\mu_{i}, D_{i}=1 \text {, if } D_{i}^{*}>0
$$

In the above formula, $D_{i}$ denotes a binary exposure variable, whose value is $D_{i}=1$ if herder $\mathrm{i}$ chooses to purchase the sheep weather index insurance, and is $D_{i}=0$ if not. Meanwhile, $Z_{i}$ represents the personal and familial vectors of herder $i$, such as age, education level and husbandry scale, $\beta$ is a coefficient vector to be estimated, and $\mu_{i}$ is the random disturbance term. Assuming $\mu_{i}$ satisfies the normal distribution of zero mean and $\sigma_{\mu}^{2}$ variance, and encompasses factors influencing

ISSN: 0010-8189 
herdsmen's choice behavior that are unobservable by the researchers, such as their inherent livestock management skills, understanding of weather index insurances and sensitivity to neighbors' purchase choices. Suppose the random disturbance term in the selection equation (1) follows a binary normal distribution with a mean of 0 and a variance of 1 , then the insurance purchasing probability of herder $i$ can be expressed by the following formula:

$$
\operatorname{Pr}\left(D_{i}=1\right)=\operatorname{Pr}\left(D_{i}^{*}>0\right)=\operatorname{Pr}\left(\mu_{i}>Z_{i} \beta\right)=1-F\left(-Z_{i} \beta\right)
$$

where $F($.$) represents the cumulative distribution function of \mu_{i}$.

Since in the selection equation, the herdsmen's intention of purchasing weather index insurance is driven primarily by changes in the final breeding scale, then the breeding scale should be treated differentially in the outcome equations.

$$
\begin{gathered}
Y_{i M}=X_{i} \beta_{i M}+\varepsilon_{i M} \text { if } D_{i}=1 \\
Y_{i N}=X_{i} \beta_{i N}+\varepsilon_{i N} \text { if } D_{i}=0
\end{gathered}
$$

In the above equations (3) and (4), $\mathrm{Y}_{\mathrm{iM}}$ and $\mathrm{Y}_{\mathrm{iN}}$ denote the final livestock quantity of herdsmen who purchased weather index insurance and the livestock quantity of those without insurance purchase, respectively. Besides, $X_{i}$ represents the personal and familial vectors of herdsmen, $\beta_{\mathrm{iM}}$ and $\beta_{\mathrm{iN}}$ are coefficient vectors to be estimated, and $\varepsilon_{\mathrm{iM}}, \varepsilon_{\mathrm{iN}}$ are the random disturbance terms. Noteworthy is that the variables in the personal and family vectors of selection equation can coincide with the variables of $\mathrm{X}_{\mathrm{i}}$ in the outcome equations. However, addition of at least one effective instrument variable is required for model identification. In other words, there must be at least one variable in the selection equation that is absent in the outcome equations. This implies that the instrumental variables affect the herdsmen's insurance purchase, but no effect on the explained variables in the outcome equations.

As described above, since the insurance purchase behavior of herdsmen relies jointly on their own observable and unobservable factors rather than being random, such self-selection will result in a serious bias problem. Meanwhile, the selection bias caused by negligence of unobservable factors will only lead to biased, inconsistent estimates ultimately. The occurrence of self-selection may lead to non-zero covariance between the random disturbance terms in the selection equation (1) and the outcome equations (3) (4). Suppose the random disturbance terms $\mu_{\mathrm{i}}$, in the selection equation and $\varepsilon_{\mathrm{iM}}, \varepsilon_{\mathrm{iN}}$, in the outcome equations follow a ternary normal distribution with a mean vector of 0 , and establish the following covariance matrix:

$$
\operatorname{cov}\left(\varepsilon_{i M}, \varepsilon_{i N}, \mu_{i}\right)=\Sigma=\left[\begin{array}{ccc}
\sigma_{i M}^{2} & \sigma_{i M i N} & \sigma_{i M \mu} \\
\sigma_{i M i N} & \sigma_{i N}^{2} & \sigma_{i N \mu} \\
\sigma_{i M \mu} & \sigma_{i N \mu} & \sigma_{\mu}^{2}
\end{array}\right]
$$

where $\operatorname{var}\left(\varepsilon_{\mathrm{iM}}\right)=\sigma_{\mathrm{iM}}^{2}, \operatorname{var}\left(\varepsilon_{\mathrm{iN}}\right)=\sigma_{\mathrm{iN}}^{2}, \operatorname{var}\left(\mu_{\mathrm{i}}\right)=\sigma_{\mu}^{2}, \operatorname{cov}\left(\varepsilon_{\mathrm{iM}}, \varepsilon_{\mathrm{iN}}\right)=\sigma_{\mathrm{iMiN}}, \operatorname{cov}\left(\varepsilon_{\mathrm{iM}}, \mu_{\mathrm{i}}\right)=\sigma_{\mathrm{iM} \mu}$ and $\operatorname{cov}\left(\varepsilon_{\mathrm{iN}}, \mu_{\mathrm{i}}\right)=\sigma_{\mathrm{iN} \mu}$. It can be found that $\varepsilon_{\mathrm{iM}}$ and $\varepsilon_{\mathrm{iN}}$ in the outcome equations have non-zero expectancies due to the sample selection criteria. Accordingly, sample selection bias will be generated if the outcome equations are regressed with least squares method, thereby deriving biased estimates. The expected values $\left(\varepsilon_{\mathrm{iM}} \mid \mathrm{D}_{\mathrm{i}}=1\right)$ and $\left(\varepsilon_{\mathrm{iN}} \mid \mathrm{D}_{\mathrm{i}}=0\right)$ of truncation error term can be calculated as follows:

$$
E\left(\varepsilon_{i M} \mid D_{i}=1\right)=E\left(\varepsilon_{i M} \mid \mu_{i}>Z_{i} \beta\right)=\sigma_{i M \mu} \frac{\varphi\left(Z_{i} \beta / \sigma\right)}{\phi\left(Z_{i} \beta / \sigma\right)} \equiv \sigma_{i M \mu} \lambda_{i M}
$$




$$
E\left(\varepsilon_{i N} \mid D_{i}=0\right)=E\left(\varepsilon_{i N} \mid \mu_{i} \leq Z_{i} \beta\right)=\sigma_{i N \mu} \frac{-\varphi\left(Z_{i} \beta / \sigma\right)}{1-\phi\left(Z_{i} \beta / \sigma\right)} \equiv \sigma_{i N \mu} \lambda_{i N}
$$

where $\varphi$ and $\phi$ represent the probability density function and cumulative distribution function that conform to the standard normal distribution, respectively, and $\lambda_{\mathrm{iM}}, \lambda_{\mathrm{iN}}$ are known as inverse Mills ratios. These inverse Mills ratios have a profoundly important place in the application of endogenous switching regression model, which are substituted into the outcome equations along with the covariance of random disturbance terms in the selection and outcome equations, in order to control the selection bias arising from unobservable factors.

$$
\begin{gathered}
Y_{i M}=X_{i} \beta_{i M}+\sigma_{i M \mu} \lambda_{i M}+\gamma_{i M} \\
Y_{i N}=X_{i} \beta_{i N}+\sigma_{i N \mu} \lambda_{i N}+\gamma_{i N}
\end{gathered}
$$

In the endogenous switching regression model, the choice of correlation coefficients $\rho_{\mathrm{iM} \mu}\left(\sigma_{\mathrm{iM} \mu} / \sigma_{\mathrm{iM}} \sigma_{\mu}\right)$ and $\rho_{\mathrm{iN} \mu}\left(\sigma_{\mathrm{iN} \mu} / \sigma_{\mathrm{iN}} \sigma_{\mu}\right)$ between the random disturbance terms of the selection and outcome equations is of great metrological significance. As repeatedly emphasized above, the biggest advantage of the model is precisely its consideration of the selection bias arising from unobservable factors and its treatment of the unobservable factors as missing variables. Accordingly, there may be factors in the random error terms of selection and outcome equations that affect the insurance purchase willingness and the husbandry scale of herdsmen simultaneously, which help establishing the correlation between the random error terms of the two equation types, i.e. $\rho_{\mathrm{iM} \mu} \neq 0$ or $\rho_{\mathrm{iN} \mu} \neq 0$. If $\rho_{\mathrm{iM} \mu}$ or $\rho_{\mathrm{iN} \mu}$ is statistically significant, there will be a selection bias resulting from unobservable factors.

In this study, whether the purchase of weather index insurance impacts the herdsmen's livestock size is investigated by the average treatment on the treated (ATT) effect. During policy evaluation, one foremost issue is to search for "counterfactual situations". The false counterfactual situations will eventually lead to erroneous evaluations. In general, there are two ways of searching for "counterfactual situations": one is the "with and without comparison", and the other is the "before and after comparison". These two methods also correspond to different data type requirements and approaches, and the endogenous switching regression model corresponds to the first method. In the present study, the difference in livestock size is investigated between the insured and uninsured herdsmen. The most ideal "with and without comparison for counterfactual situation" is to explore the difference in a certain research target among the same group of people in the presence or absence of a certain policy. However, this issue must be investigated under some assumptions, since simultaneous research in both scenarios is impossible.

The most common expression for average effect is given below:

$$
D=E\left(Y_{i}(1) \mid T_{i}=1\right)-E\left(Y_{i}(0) \mid T_{i}=0\right)
$$

For the convenience of presentation, the following ATT derivation processes are all based on the present research background. In the foregoing formula, for instance, $T_{i}=1$ and $T_{i}=0$ represent the purchase and non-purchase of weather index insurance by herdsmen, respectively, $\mathrm{Y}_{\mathrm{i}}(1)$ denotes the livestock size of herdsmen who purchased the insurance, and $Y_{i}(0)$ denotes the livestock size of those without insurance purchase. The conditional expectation difference D between the two groups represents the average effect. However, given the disparities among herdsmen in the treatment and control groups (insured and uninsured) regarding some unobservable factors apart from such observable factors as age and education level, the final evaluation result is bound to be erroneous if only the average effect $\mathrm{D}$ is used as the result. Hence, a simple transformation is made to the average effect D: 


$$
\begin{aligned}
& D=E\left(Y_{i}(1) \mid T_{i}=1\right)-E\left(Y_{i}(0) \mid T_{i}=0\right)+E\left(Y_{i}(0) \mid T_{i}=1\right)-E\left(Y_{i}(0) \mid T_{i}=1\right) \\
\Rightarrow & D=A T T+E\left(Y_{i}(0) \mid T_{i}=1\right)-E\left(Y_{i}(0) \mid T_{i}=0\right) \\
\Rightarrow & D+A T T+B
\end{aligned}
$$

where $\mathrm{E}\left(\mathrm{Y}_{\mathrm{i}}(1) \mid \mathrm{T}_{\mathrm{i}}=1\right)-\mathrm{E}\left(\mathrm{Y}_{\mathrm{i}}(0) \mid \mathrm{T}_{\mathrm{i}}=1\right)$ is referred to as ATT, and B denotes the degree of selection bias. The value of $\mathrm{B}$ can be assumed to be zero herein, since the endogenous switching regression model explains the selection biases arising from observable and unobservable factors, and controls the unobservable factors with inverse Mills ratios. Accordingly, D=ATT.

Finally, the endogenous switching regression model regresses the selection and outcome equations simultaneously by employing the full-information maximum likelihood method, thereby obtaining consistent standard errors. In this way, the erroneous estimates produced by segmented regression of the equations are avoided.

Using Stata 15, the following results are obtained:

\begin{tabular}{|c|c|c|c|}
\hline \multirow{2}{*}{ Variable } & \multirow{2}{*}{$\begin{array}{l}\text { Selection equation } \\
\text { (Insured/Uninsured) }\end{array}$} & \multicolumn{2}{|c|}{ Outcome equation (ln (mutton sheep inventory)) } \\
\hline & & Insured group & Uninsured group \\
\hline Age & $0.154(2.14)^{*}$ & $0.112(1.62)$ & $0.00627(0.16)$ \\
\hline Age squared & $-0.00155(-2.04)^{*}$ & $-0.00116(-1.55)$ & $-0.000147(-0.38)$ \\
\hline Years of education & $0.0454(1.47)$ & $-0.0133(-0.68)$ & $-0.0334(-1.67)$ \\
\hline Years of grazing & $-0.00663(-0.57)$ & $-0.0139(-1.92)$ & $-0.00736(-0.94)$ \\
\hline Household labor force & $-0.0222(-0.22)$ & $0.211(3.17)^{* * *}$ & $0.0341(0.54)$ \\
\hline $\begin{array}{c}\text { Experience as a village } \\
\text { cadre }\end{array}$ & $0.0720(0.29)$ & $0.0257(0.18)$ & $-0.0903(-0.46)$ \\
\hline $\begin{array}{c}\text { Distance from the } \\
\text { nearest township } \\
\text { government }\end{array}$ & $0.00104(0.29)$ & $-0.00460(-2.30)^{*}$ & $0.00250(0.98)$ \\
\hline Ln (pasture area) & $-0.226(-2.26)^{*}$ & $0.279(4.22)^{* * * *}$ & $0.496(6.65)^{* * * * *}$ \\
\hline Net pastoral income & $0.000000689(0.95)$ & $0.000000813(2.27)^{*}$ & $0.00000193(3.68)^{* * *}$ \\
\hline Forage cost & $-0.000000861(-0.43)$ & $0.00000349(2.93)^{* *}$ & $0.000000806(0.69)$ \\
\hline Shed area & $0.000370(1.60)$ & $-0.000103(-1.11)$ & $-0.000400(-2.08)^{*}$ \\
\hline Housing area & $-0.000312(-0.35)$ & $0.000341(0.67)$ & $-0.00140(-1.88)$ \\
\hline $\begin{array}{c}\text { Commercial life } \\
\text { insurance expenses }\end{array}$ & $-0.00000195(-0.16)$ & $-0.0000160(-2.27)^{*}$ & $-0.00000823(0.96)$ \\
\hline Grassland quality & $-0.0273(-0.29)$ & $0.0495(0.89)$ & $0.0201(0.30)$ \\
\hline $\begin{array}{c}\text { Grazing capacity } \\
\text { specification }\end{array}$ & $0.239(1.31)$ & $-0.127(-1.06)$ & $0.335(2.64)^{* *}$ \\
\hline $\begin{array}{c}\text { Neighbors' purchasing } \\
\text { intention }\end{array}$ & $1.193(6.96)^{* * *}$ & & \\
\hline$\rho_{i N \mu}$ & & & -0.1444201 \\
\hline$\rho_{i M \mu}$ & & -0.1100205 & \\
\hline
\end{tabular}

Table 3 Full-information maximum likelihood regression results with the endogenous switching regression model

Note: $* * *$ and $* * *$ indicate statistical significances at $10 \%, 5 \%$ and $1 \%$, respectively; the numbers in parentheses represent $t$ values

In Table 3, the second column lists the regression results for factors affecting herdsmen's insurance

ISSN: 0010-8189 
purchasing propensity. Among these factors, the age and age squared are significant at a $10 \%$ level. Moreover, the sign of variable age is positive, while the sign of age squared is negative. This suggests that the probability of a herder purchasing mutton sheep weather index insurance is not linearly related to age, two of which exhibit an inverted-U correlation. Meanwhile, the pasture area differs significantly from zero, whose sign is negative, suggesting that the herdsmen with larger pasture management areas are less likely to purchase the insurance. The probable explanation is as follows: since the mutton sheep weather index insurance covers the risk of increased forage costs among sheep herders caused by natural disasters (blizzards and droughts), those herdsmen possessing larger pasture areas are unwilling to spend extra money on it, who have a strong ability to resist risks arising from natural disasters, and believe that the forage grasses grown in their own pastures are sufficient to feed their livestock. In the endogenous switching regression model, neighbors' insurance purchasing intention is deemed as an instrumental variable. That is, whether neighbors purchase the mutton sheep weather index insurance affects the herdsmen's propensity to purchase the insurance, which though produces insignificant impact on their mutton sheep inventory.

The fourth and fifth columns in Table 3 detail the estimates concerning the impact of insurance purchase on the mutton sheep inventory. As is clear, the number of family labors is significantly positively correlated with the sheep inventory of insured herder households, while has an insignificant effect for the uninsured households. In the regression results of mutton sheep inventory amongst the insured households, the distance from the nearest township government differs significantly from zero, whose sign is negative. Suggestively, closer to the township government means closer to the market, which provides better convenience for the herdsmen to sell livestock and acquire market information, so that they are more willing to raise more mutton sheep. The pasture area, with a positive sign, has a significant impact on the mutton sheep inventory for both the insured and uninsured households. Nevertheless, regardless of the usage of livestock, the herdsmen's livestock size is subject to the grass-livestock balance policy in China. Since herders can only raise the livestock within the specified quantity ranges, those having larger pastures will choose to raise more mutton sheep. Net pastoral income exhibits a significant positive impact on the mutton sheep inventory of both the insured and uninsured groups. Driven by economic factors, rational herders will choose to expand their income by raising more mutton sheep. Thus, herder households with higher net pastoral incomes have larger mutton sheep inventories. Regarding forage cost, it has a significant positive effect on the mutton sheep inventory of the insured households, although is insignificantly influential to the uninsured group. This indicates that the insured herdsmen with higher forage expenditures raise more mutton sheep. The probable explanation is that the insured herdsmen understand the current insurance liabilities of the weather index insurance more clearly than the uninsured herdsmen. As for the shed area, its impact on the mutton sheep inventory of uninsured herdsmen is statistically significant at a $10 \%$ level, while is insignificant for the insured group. In addition, commercial life insurance expenses are significantly negatively correlated with the mutton sheep inventory of the insured households, while the national regulations on grazing capacity exert a significant positive impact on the mutton sheep inventory amongst the uninsured herdsmen.

Table 4 ATT results of mutton sheep weather index insurance on the sheep farming scale

\begin{tabular}{|c|c|c|c|c|c|}
\hline \multirow{2}{*}{ Variable } & \multicolumn{2}{|c|}{ Mean } & \multirow{2}{*}{$\begin{array}{l}\text { (ATT) } \\
\text { ATT }\end{array}$} & \multirow{2}{*}{$\mathrm{t}$ value } & \multirow{2}{*}{$\begin{array}{l}\text { Variation } \\
\qquad \%)\end{array}$} \\
\hline & Insured group & Uninsured group & & & \\
\hline $\begin{array}{l}\text { Ln (mutton sheep } \\
\text { inventory }\end{array}$ & $5.82(0.49)$ & $5.76(0.62)$ & 0.06 & 0.8308 & 1.04 \\
\hline
\end{tabular}

In Table 4, the ATT estimate of the mutton sheep weather index insurance on the herdsmen's breeding scale is presented, which differs from the simple mean comparisons and significance tests in Table2. Taking both the observable and unobservable factors into consideration, the ATT results after endogenous switching regression resolve the selection bias problem. According to Table 4, the ATT

ISSN: 0010-8189 
estimate is 0.06 , and the mutton sheep weather index insurance can facilitate the sheep inventory growth for herders by $1.04 \%$. Nevertheless, the ATT value fails the significance test, indicating an insignificant impact of the insurance on the sheep breeding scale. Regarding possible reason, the mutton sheep farming in China's pastures is affected greatly by factors like markets, land resource endowments and policies at present. The mutton sheep weather index insurance, as a risk control tool, can hardly exert any significant impact on the sheep farming scale of herdsmen currently.

\section{Conclusions and policy implications}

In this study, the endogenous switching regression model is utilized to analyze the factors influencing herdsmen's propensity to purchase mutton sheep weather index insurance simultaneously with the impact of such insurance on the sheep farming scale, which are achieved based on 308 field survey data from herdsmen in the Xilin Gol League, Inner Mongolia Autonomous Region. The endogenous switching regression model considers the effects of both observable and unobservable factors on the research topic concurrently, thus avoiding the selection bias problem. As the empirical results show, the age, age squared, pasture area and neighbors' purchasing intention are all significantly influential to the herdsman's purchasing decisions. Finally, the ATT results reveal that the mutton sheep weather index insurance exerts an insignificant impact on the sheep farming scale of surveyed herdsmen at present.

According to the survey and interview findings in the case of Zhenglan Banner in Xilin Gol League, the banner government is currently somewhat resisting the promotion of mutton sheep weather index insurance affected by the autonomous region's cattle-increasing, sheep-reducing policy, claiming that the insurance contradicts the policy. The relevant governmental authorities of the banner pinpointed that with the aim of adjusting the husbandry structure and protecting the grassland ecosystem, the banner has implemented the cattle-increasing, sheep-reducing policy in active response to the autonomous region's call, which has achieved certain outcomes. However, the implementation of the index insurance may somewhat mislead the herders to believe it as a signal from the government for encouraging the mutton sheep husbandry. As a result, the sheep farming scale of herdsmen may increase indirectly, thereby affecting the early implementation outcomes of the insurance. According to the present empirical results, the implementation of mutton sheep weather index insurance currently has an insignificant impact on the sheep farming scale of herdsmen. Thus, the conclusions of this study can eliminate the concerns of Zhenglan and other relevant governments, which lay a solid theoretical foundation for the future promotion of the insurance throughout the Inner Mongolia Autonomous Region.

\section{Acknowledgements}

This research was supported by National Natural Science Foundation of China (Grant No. 71863028; 71563037).

This research was supported by Science and Technology Projects of Inner Mongolia Autonomous Region (Grant No. 201802108).

\section{Reference}

[1] Y.H. Zhang. "Foreign agricultural weather index insurance exploration," China rural economy, vol. 396 , no. 12, pp. 81-92, 2017.

[2] S. Chantarat, A.G. Mude, "Barrett C B , et al. Welfare Impacts of Index Insurance in the Presence of a Poverty Trap," World Development, vol. 94, pp. 119-138, 2017.

[3] M.J. Miranda, K. Farrin. "Index insurance for developing countries," Applied Economic Perspectives and Policy, vol. 34, no. 3, pp. 391-427, 2012.

[4] U. Hess, J.R. Skees, A. Stoppa, et al. "Managing agricultural production risk: Innovations in ISSN: 0010-8189 
developing countries," Agriculture and Rural Development (ARD) Department Report, 2005 (32727-GLB).

[5] N.D. Jensen, C.B. Barrett, "Mude A G. Index insurance quality and basis risk: evidence from northern Kenya," American Journal of Agricultural Economics, vol. 98, no. 5, pp. 1450-1469, 2016.

[6] Barnett B J , Mahul O . Weather Index Insurance for Agriculture and Rural Areas in Lower-Income Countries. American Journal of Agricultural Economics, 2007, 89(5):1241-1247.

[7] Ding Shaoqun, Luo Ting. Evaluation of pilot weather index insurance in China. Shanghai insurance, 2017 (5): 56-61

[8] Jensen N D, Barrett C B, Mude A G. Basis risk and the welfare gains from index insurance: Evidence from northern Kenya. 2014.

[9] P.B.R. Hazell, U. Hess. "Drought insurance for agricultural development and food security in dryland areas," Food Security, vol. 2, no. 4, pp. 395-405, 2010.

[10] M.J. Miranda, K. Farrin. "Index insurance for developing countries," Applied Economic Perspectives and Policy, vol. 34, no. 3, pp. 391-427, 2012.

[11] V. Smith, M. Watts. "Index based agricultural insurance in developing countries: Feasibility, scalability and sustainability,” Gates Foundation, pp. 1-40, 2009.

[12] Marcel, Fafchamps. The Tragedy of the Commons, Livestock Cycles and Sustainability. J Afr Econ, 1998.

[13] W. Ma, A. Abdulai. "Does cooperative membership improve household welfare? Evidence from apple farmers in China," Food Policy, vol. 58, pp. 94-102, 2016.

[14] M. Lokshin, Z. Sajaia. "Impact of interventions on discrete outcomes: maximum likelihood estimation of the binary choice models with binary endogenous regressors", Stata Journal, vol. 11, no. 3, pp. 368-385, 2011. 